\title{
Suffixes Forming Adjective Found in the Novel Peter Pan
}

\author{
Falentinus Ndruru ${ }^{1}$, Mirsa Umiyati ${ }^{2}$, I Gede Prima Wijaya ${ }^{3}$ \\ Master of Linguistik Program, Universitas Warmadewa ${ }^{1,2}$, Faculty of Letters, Universitas \\ Warmadewa Denpasar-Bali, Indonesia ${ }^{3}$ \\ \{falentinusndruru@gmail.com ${ }^{1}$, mirsa.umiyati2@gmail.com², primawijaya@gmail.com ${ }^{3}$ \}
}

\begin{abstract}
This study aims to describe the suffixes forming adjective found in the Novel Peter Pan and the bases that are possibly changed into adjective. The data of this research were taken from the novel entitled Peter Pan by J.M Barrie. The main theory which is used in analyzing the data is theory of suffixes by Bauer (1983). The data were collected by reading. After collecting, the data were classified based on scope discussions. The result showed that there are six kinds of part of speech that were found, namely; noun, verb, adverb, adjective, conjunctions, pronoun. Suffix forming adjective is the process of forming adjective by adding suffixes to another word class. In the data, it is found that there are three kinds of word class bases that can be attached with suffixes to form adjective, they are noun base, verb base, and adjective base. Furthermore, based on the result of the research which was described descriptively, it can be concluded that suffixes forming adjective there are some points that can be taken as the conclusion.
\end{abstract}

Keywords: Element of Adjective; Morphemes; Suffixes; Word Class

\section{Introduction}

People use words in language when they communicate with other people. In English, there are many words, as one or more morpheme that can stand alone in a language [1], that includes in the elements of sentence such as noun, verb, adverb, adjective, preposition, and so on [2]. The study related to words forming is called morphology. To know deeply about words especially about class words, the lexeme, word-form, and the grammatical word, we must learn morphology. Morphology as a sub-branch of linguistic deals with the internal structure of word-forms [3], the basic units of analysis recognized in morphology are morphemes, is the smallest difference in the shape of a word that correlates with the smallest difference in word or sentence meaning or in grammatical structure [4]. Consider, for example the word-form untouchable, this can be segmented to show its constituent elements thus: un + touch + able $+s$. Each of these segments has its own form (or set of forms), its own meanings, and its own distribution.

There are two kinds of morpheme, namely free morpheme and bound morpheme. Free morpheme is morpheme that can stand by itself, like man, book, tea, sweet and Bound morpheme is morpheme that cannot stand alone such as suffix -er, -s. In learning about 
morpheme, we have to understand root, stem and base. Root, stem and base are free morphemes that have not attached with any affixes, for example: book. The word book is free morpheme which has not attached with any affixes. Root is the reducible core of a word with nothing else attached on it, stem is the part of word that is existence before any inflectional suffixes have been added and base is any unit whatever to which suffixes of any kind be added. Suffix is a morpheme added at the end of a word to form a derivative.

\section{Beauty-ful function-al artist-ic}

Break-able home-less nice-r

In the first example, suffix -ful turns the noun "beauty" into adjective "beautiful". This condition shows that suffixes are very complex, for them may turn certain words into different word class. Suffix is a word the end which change the meaning. The complexity of suffixes can one be found in the novel due to novel is a formal English language in the form of written that suffixes can be identified easily.

The following section would be pertained some latest research regarding to this current issue. Firstly, a research carried out by [5], the finding showed that positioned higher profitability of theoretical thing framing additions, for example, - ity, - ion and - ness in logical registers than in the BNC. The suffix - ize arrived at values in the logical corpora profoundly over the positioning drawn from the BNC. Despite what might be expected, the BNC yielded an exceptional profitability pace of - free and - like, suffixes which end up being completely ineffective in the logical registers under investigation.

Secondly, a research conducted [6] utilize the computer in analyzing their data. Finally, the result showed that suffix trees are naturally unbalanced: prefix augmentations just purpose a several updates, while suffix expansions influence all suffixes causing a flood of updates. In his exquisite direct time on-line suffix tree calculation Ukkonen loosened up the overall suffix tree portrayal and acquainted two changes with stay away from rehashed structural updates and bypass the inalienable unpredictability of suffix expansions: (1) open finished edges that appreciate unwarranted leaf updates, and (2) the oversight of certain hubs. Therefore, the study of suffixes is really important to be conducted since considering it really helpful students. This study was focused on the suffix forming adjective. The aims of this study were to describe the suffixes forming adjective found in the novel Peter pan and the bases that are possibly changed into adjective.

\section{Method}

The data source of this research is taken from the novel entitled Peter Pan written by Barrie [7]. This novel chosen as the data source due to the novel is written by native speaker and the writer used formal English language. In collecting the data, firstly, the novel was red carefully, and then all the relevant sentences containing the suffixes are quoted and classified by taking a note. Furthermore, the data that have been collected would be analyzed based on the form suffixes attached to the words. Then, the result of the research would be presented into sequences of paragraphs and interpreted by giving the description. 


\section{Result and Discussion}

\subsection{Suffixes Forming Adjective Attached to Noun}

There are some suffixes that can be attached to the adjectives to form noun. Based on the finding from the data source, the suffixes which can be attached to: -ful, -less, -ic.

\subsubsection{Suffix - ful}

Suffix -ful is usually added to noun base. When the suffix -ful is attached to a noun base, the suffixis usually mean "full of" or "having". Suffix -ful is added to noun to produces new lexeme which belongs to word class of an adjective and have different meaning.

a. What he didn't realize was that the steadfast Liza had discovered it, and set it back on his wash-stand [7].

b. At first he pooh-poohed the story, yet he became insightful when she demonstrated him the shadow [7].

c. It was awful the manner in which all the three were taking a gander at him, similarly as though they didn't respect him [7].

In the example (1), show the adjective faithful is derived from noun base faith and attached by suffix $-f u l$, so that is becomes faithful. In this case suffix $-f u l$ here produces adjective from noun. The suffix -ful in the word faithful has meaning of "full of" or "having". The base is faithful which is a noun, the meaning is complete trust or confidence in someone or something.

Suffix -ful can also be seen in the example (2), the adjective thoughtful is formed through the derivational process, which is formed by noun base thought, and suffix $-f u l$ so that it becomes thoughtful. The suffix $-f u l$ here is called the suffix forming adjective from noun. The meaning of the suffix -ful in the word thoughtful is having "a thought". The base is thought which can be either verb or noun.

The word dreadful in the example (3) belongs to derived word. The base of word dreadful is from the noun base dread that gets a changing by adding suffix -ful, so that it becomes dreadful. The suffix - ful in the word dreadful has a meaning "having dread". The base is dread which can be either noun, verb, and adjective. As noun it means great fear or apprehension. As verb it means anticipate with great apprehension or fear. As adjective it means greatly feared; dreadful.

\subsubsection{Suffix -less}

Suffix -less is usually added to a noun base. When suffix -less attached to a noun base, the suffix is usually mean "does not have" or "without". This suffix is used to form an adjective.

a. She had always thought children important, however, and the Darling had become acquainted with her in Kensington Gardens, where she spent most of her spare time peeping into perambulators, and was much hated by careless nursemaids, whom she followed to their homes and complained of to their mistresses [7].

b. If you shut your eyes and are a good for one, you will see on occasion an unclear pool of dazzling pale tones suspended in the murkiness; at that point on the chance that you crush your eyes more tight, the pool starts to come to fruition, and the tones become so distinctive that with another press they should go ablaze.

c. Once more the boys emerged into the open; but the dangers of the night were not yet over, for presently Nibs rushed breathless into their midst, pursued by a pack of wolves [7]. 
The bold word careless in the example (1) is formed by noun base care, and suffix -less so that it becomes careless. The suffix -less here is called the suffix forming adjective from noun, it derives from noun care into adjective careless. The meaning of careless is "having sloppy". The base care which can be noun and verb. As noun it implies the arrangement of what is important for the wellbeing, government assistance, support, and assurance of a person or thing or genuine consideration or thought applied to accomplishing something effectively or to dodge harm or danger. As action word it implies feel concern or intrigue; join significance to something or care for and accommodate the requirements of.

In the example (2), the adjective shapeless is derived from noun base shape and attached by suffix -less. So that it becomes shapeless. In this case suffix -less here produce adjective from noun. The suffix -less in the word shapeless has meaning "does not have shape or without shape". The base shape which can be either noun and verb. As noun it means the external form or appearance characteristic of someone or something; the outline of an area or figure or the particular condition or state of someone or something. As verb it means give a particular shape or form to.

The word breathless in the example (3) is formed through derivational process, which is derived from noun base breath and added by suffix -less. The conjoining of suffix -less and the noun base breath form the new class breathless which belongs to adjective. The meaning of suffix -less in the word breathless is "having breath of fresh air". The base breath is a noun which means the air taken into or expelled from the lungs.

\subsubsection{Suffix -ic}

Suffix - ic can be added to noun which changes the word class from noun into adjective. When suffix -ic attached to noun base, the suffix usually means "like a or "connecting with".

a. Peter never fully recognized what twins were, and his band were not permitted to know anything he didn't have the foggiest idea, so these two were consistently unclear about themselves, and put forth a valiant effort to give fulfillment by keeping near one another in a contrite kind of way [7].

b. She was an exquisite woman, with a sentimental psyche and such a sweet taunting mouth [7].

The word apologetic in the example (1) is formed through derivational process, which is derived from noun base apology and added by suffix $-i c$. The conjoining of suffix $-i c$ and the noun base apology form the new class apologetic which belongs to adjective. The meaning of suffix $-i c$ in the word apologetic is "having feel regretful". The base apology is noun which means a regretful acknowledgment of an offense or failure or a very poor or inadequate example of.

Based on the example (2), the bold word romantic comes though derivational process, which is derived from noun base romance and added by suffix -ic. So that it becomes romantic, in this case suffix -ic here produces adjective from noun. The suffix $-i c$ in the word romantic has meaning of "having feel romance". The base romance can be either noun or verb. As noun it means a feeling of excitement and mystery associated with love or a quality or feeling of mystery, excitement, and remoteness from everyday life. As verb it means court; woo or another term for romanticize. 


\subsection{Suffixes Forming Adjective Attached to Verb}

Based on the finding from the data source, suffixes forming adjective that can be attached to verb base namely suffix - able and suffix -ing.

\subsubsection{Suffix - able}

a. Mr. Darling was fightfully pleased with her, yet he was truly fair, and he sat on the edge of Mrs [7].

b. The redskins vanish as they have come like shadows, and soon their place is taken by the monsters, an extraordinary and diverse parade: lions, tigers, bears, and the multitudinous more modest savage things that escape from them, for everything about, and, all the more especially, all the man-eaters, live cheek by cheek on the supported island [7].

c. A man of unyielding boldness, it was said that the main thing he shied at was seeing his own blood, which was thick and of an unusual colour[7].

Based on the example (1), the adjective honourable is derived from noun base honour and attached with suffix -able. The attachment of the suffix -able changes the base word class from noun into adjective. In this case, suffix -able is called suffix forming noun. Suffix -able in the word honourable has meaning "having honour". The base honour can be either noun or action word. As thing it implies high regard; regard or a benefit. As action word it implies respect with incredible regard or satisfy (a commitment) or keep (an arrangement).

Seen from example above, the sentence number (2) shows the word innumerable is derived from verb base numerate attached by suffix -able. The conjoining of suffix -able and the verb base numerate forming the new class innumerable which belongs to adjective. And the meaning of suffix -able in the word innumerable is "having countless". The base numerate is adjective which means having a good basic knowledge of arithmetic; able to understand and work with numbers.

The adjective indomitable in sentence number (3) is derived from verb base dominate and added by suffix -able. The conjoining of suffix - able and the verb base dominate form the new class indomitable which belongs to adjective. And the meaning of suffix -able in the word indomitable is "having feel persistent". The base dominate is verb which means have a commanding influence on; exercise control over.

\subsubsection{Suffix -ing}

Suffix -ing can be added to a verb base, it can form noun in the form of derivative noun or gerund. It can also be used to form adjective as present participle; -ing form functions as verb or adjective. Meanwhile as gerund, -ing form functions as noun.

a. How might she be able to stand up to. "Obviously it's terribly intriguing!" [7].

b. It's awfully puzzling," said Tootles, who knew the story by heart [7].

c. They all assembled round him in dismay, so disturbing was his unsettling; and with a fine realism he mentioned to them what he had up to this point covered [7].

Based on the example above, the sentence number (1) shows the word disturbing is derived from verb base disturb attached by suffix -ing. The conjoining of suffix -ing and the verb base disturb forming the new class disturbing which belongs to adjective. And the meaning of suffix -ing in the word disturbing is "should not be disturbed". The base disturb is verb which means interfere with the normal arrangement or functioning of. 
In sentence number (2), an adjective telling is derived from verb base tell attached by suffix -ing. The conjoining of suffix -ing and the verb base tell forming the new class telling which is belongs to adjective. And the meaning of suffix -ing in the word telling is "having tell stories". The base tell can be either verb or noun. As verb communicate information, facts, or news to someone in spoken or written words or decide or determine correctly or with certainty. As noun it means (particularly in poker) an oblivious activity that is thought to deceive an endeavored double dealing.

The word wearing in the sentence number (3) is derived from verb base wear attached by suffix -ing. The conjoining of suffix -ing and the verb base wear forming the new class wearing which belongs to adjective. And the meaning of suffix -ing in the word wearing is "having feel wear dress". The base wear can be either verb or noun. As verb it means have on one's body or a part of one's body as clothing, decoration, protection, or for some other purpose or damage, erode, or destroy by friction or use. As noun it means the wearing of something or the state of being worn as clothing or clothing suitable for a particular purpose or of a particular type.

\subsection{Suffixes Forming Adjective Attached to Adjective}

Suffixes forming adjective that can be attached to adjective that found in data source are suffix - er and suffix - est. When a word formed by attaching a suffix forms an adjective from an adjective base, the suffix does not change the base word class. The kinds of suffixes can be seen as follow.

\subsubsection{Suffix - er}

The suffixes -er and -est may be used to form the comparative and superlative of most adjectives and adverbs that have one syllable and some that have two or more syllables.

a. They started the stanza, however they never completed it, for another sound broke in and stilled them. There was from the start such a small stable that a leaf may have fallen on it and covered it, yet as it came closer it was more particular[7].

b. The rock was not a lot bigger than their extraordinary bed, but rather obviously they all knew how not to occupy a lot of space, and they were snoozing, or possibly lying with their eyes shut, and squeezing at times when they thought Wendy was not looking[7].

c. A more limited experience, and very as energizing, was Tinker Bell's endeavor, with the assistance of some road pixies, to have the resting Wendy passed on an extraordinary gliding leaf to the terrain [7].

Seen from the example above, the sentence number (1) the adjective nearer is derived from adjective base near and added by suffix -er. The attachment of the suffix -er does not change the base word class, and it is called inflectional process. The meaning of suffix -er in the word long is "comparative degree of near". The base near can be either adverb, preposition, adjective, verb. As adverb it means at or to a short separation away; close by or a brief timeframe away later on. As relational word it implies at or to a short good ways from (a spot) or a brief timeframe from. As adjective it means found a short separation away or just a brief timeframe ahead. As verb it means come near to (someone or something); approach.

The adjective larger in sentence number (2) is derived from adjective base large and added by suffix $-e r$. The attachment of the suffix $-e r$ with the adjective base does not change the base word class, and it is called inflectional process. The meaning of suffix $-e r$ in the word larger is 
"comparative degree of large". The base large is an adjective which means of considerable or relatively great size, extent, or capacity or of wide range or scope.

Shorter as we can see in the example number (3) above is derived from adjective base short and added by suffix $-e r$. The attachment of the suffix $-e r$ with the adjective base does not change the base word class, and it is called inflectional process. The meaning of suffix $-e r$ in the word shorter is "comparative degree of short". The base short can be either adjective or verb. As adjective it means measuring a small distance from end to end or lasting or taking a small amount of time. As verb it means short-circuit or cause to short-circuit.

\subsubsection{Suffix -est}

Suffix - est can be attached to an adjective base. This suffix is used to form an adjective. When suffix - est attached to an adjective base, the suffix - est may mean "superlative degree" or "most".

a. ..., but Wendy would have [desired] a baby, and he was the littlest, and you know what women are, and the short and long of it is that he was hung up in a basket [7].

b. This is the closest you actually get to it on the territory, only one magnificent second; if there could be two minutes you may see the surf and hear the mermaids singing [7].

c. First off he scorned all moms aside from Wendy, and for another he was the main kid on the island who could neither compose nor spell; not the littlest word [7].

Based on the example (1) the adjective littlest is derived from adjective base little and added by suffix - est. The attachment of the suffix - est with the adjective base does not change the base word class, and it is called inflectional process. The meaning of suffix -est in the word littlest is "most little". The base is little which is an adjective, the meaning is small in size, amount, or degree (often used to convey an appealing diminutiveness or express an affectionate or condescending attitude). The base little can be either adjective, determiner, adverb. As adjective it means small in size, amount, or degree (often used to convey an appealing diminutiveness or express an affectionate or condescending attitude). As determiner it means a small amount of. As adverb it means to a small extent.

In the example (2) the adjective nearest is derived from adjective base near and added by suffix - est. the attachment of the suffix - est with the adjective base does not change the base word class, and it is called inflectional process. The meaning of suffix -est in the word nearest is "superlative of degree near". The base near can be either adverb, preposition, adjective, verb. As adverb it means at or to a short separation away; close by or a brief timeframe away later on. As relational word it implies at or to a short good ways from (a spot) or a brief timeframe from. As adjective it means found a short separation away or just a brief timeframe ahead. As verb it means come near to (someone or something); approach.

Suffix - est can also be seen in the example number (3) the adjective smallest is derived from adjective base small and added by suffix - est. The attachment of the suffix - est with the adjective base does not change the base word class, and it is called inflectional process. The meaning of suffix - est in the word smallest is "most small". The base small can be either adjective or adverb. As adjective it means of a size that is less than normal or usual. As adverb it means into small pieces. 


\section{Conclusion}

Based on the result above, the conclusion that can be made were there are six kinds of part of speech that were found, namely; noun, verb, adverb, adjective, conjunctions, pronoun. Suffix forming adjective is the process of forming adjective by adding suffixes to another word class. In the data, it found that there are three kinds of word class bases that can be attached with suffixes to form adjective, they are noun base, verb base, and adjective base. Suffix forming adjective which is found in the data are suffixes forming adjective attached to noun, attached to verb, and attached to adjective. Suffixes forming adjective found in the data are suffix -ful, less, -ic, -able, -ing, and -er.

\section{References}

[1] R. Lieber, Introducing Morphology. New York: Cambridge University Press, 2009.

[2] S. Quirk, Randolph and Greenbaum, A University Grammar of English. London: Longman Group, 1973.

[3] L. Bauer, English - Word Formation. Cambridge: Cambridge University Press, 1983.

[4] F. Katamba, Morphology. Houdmills: Macmillan Press LTD, 1993.

[5] B. M. Fleta, "Suffixes in word-formation processes in scientific English," LSP Journal - Professional Communication, Knowledge Management and Cognition, vol. 2, no. 2, pp. 4-14, 2011.

[6] D. Breslauer and G. F. Italiano, "On suffix extensions in suffix trees," Theoretical Computer Science, vol. 457, pp. 27-34, 2012.

[7] J. . Barrie, Peter Pan. USA: University U.S.A Library, 2014. 